\title{
Blue genes
}

\section{Three genes linked to bipolar affective disorder}

Affective disorder tends to run in families. The risk to relatives depends on whether the proband suffers from bipolar or unipolar illness - that is, manic depression or recurrent depression; the average lifetime risk of affective disorder in the first degree relatives of a patient with a unipolar illness is about $9 \%$ and roughly double that when the patient has a bipolar illness. The higher risk to the relatives of patients with bipolar illness implies that bipolar illness is under greater genetic influence than unipolar illness, and this has been confirmed by studies in twins ${ }^{1}$ and in the adoptedaway children of manic-depressive patients. ${ }^{2}$ It was therefore logical to apply the techniques of molecular genetics to bipolar disease and to study the interaction between genes and environment in patients with unipolar illness. Both these approaches have recently born exciting if unexpected fruit.

Several groups have carried out linkage studies in those families of patients with bipolar illness that contain many other cases. The breakthrough came from research among the old order Amish, a religious community in Pennsylvania that is cut off from the outside world and in which families could be examined back through several generations. In one pedigree of 81 members linkage was found between the occurrence of illness (in 19 people) and two markers on chromosome 11, the insulin gene, and the cellular oncogene C-Harvey-ras-1..$^{3.5}$ This suggests that in this pedigree at least a dominant gene that confers a strong predisposition to bipolar disorder lies on the tip of the short arm of chromosome 11. The structural gene for tyrosine hydroxylase is located in this area and is a possible candidate for the proposed locus for the disease, but O'Malley and Rotwein suggest that it may not be in precisely the right position. ${ }^{6}$

The gene on chromosome 11 does not, however, seem to account for most cases of bipolar disorder because two studies - one of North American ${ }^{7}$ and the other of Icelandic pedigrees $^{8}$ - have ruled out linkage of the insulin and CHarvey-ras-1 genes to bipolar disorder. Further evidence for genetic heterogeneity has come from recent studies showing linkage between bipolar disorder and markers on the $\mathrm{X}$ chromosome in several Israeli and Belgian families. ${ }^{9}{ }^{10}$ Yet $\mathrm{X}$ linkage was ruled out by father to son transmission in the American and Icelandic pedigrees, ${ }^{78}$ so possibly at least three genes may predispose to bipolar disorder: one on the $\mathrm{X}$ chromosome, one on chromosome 11 , and one or more elsewhere.

The priorities now must be to establish the prevalence of $\mathrm{X}$ linked bipolar illness and whether the chromosome 11 linkage may be replicated outside the genetically isolated Amish community. Methodological hazards await the molecular geneticist who strays into the psychiatric arena, ${ }^{11}{ }^{12}$ but most militate against finding linkage. The greatest pitfall is defining the affected phenotype-for example, in the Amish study relatives without bipolar disorder were scored as affected if they had suffered from schizoaffective disorder, atypical psychosis, or major depression. A good case can be made for including these disorders because of their genetic relation to bipolar illness. Indeed, linkage studies may illuminate such relations by helping us to understand the range of phenotypic abnormality that can result from defects at a single locus. This may eventually mean that psychiatric disorders can be defined aetiologically rather than phenomenologically. In the short term, however, investigators must beware of generating spuriously inflated estimates of linkage by manipulating the definition of an affected case.

In ordinary unipolar depression genetic transmission is likely to be polygenic and the social environment at least as important as the genetics. You might suppose that people with a strong family diathesis for affective disorder would need fewer adverse environmental events to succumb to depression than those without affected relatives, but the recently completed Camberwell collaborative depression study has disproved this prediction. ${ }^{13}$ Indeed, the relatives of probands whose depression followed life events or long term difficulties had slightly higher rates of depression in their lifetimes than the relatives of probands whose illness began without associated adversity. An even more unexpected finding was that the relatives of depressed probands were significantly more likely to have suffered threatening life events in the period before the interviews than a sample from the community. These events did not follow the turmoil caused by the proband's illness. The intriguing possibility is thus raised that some people may either inherit or learn from their parents the propensity to encounter adversity.

The blues singer Memphis Slim used to sing:

$$
\begin{aligned}
& \text { My mama had them; } \\
& \text { Her mama had them; } \\
& \text { Now I've got them too; } \\
& \text { Folks, you've got to inherit the blues. }
\end{aligned}
$$

He was right about bipolar disorder, for which there seems to be at least three different "blue" genes. In people who 
suffer from unipolar depression the cause is more complicated: their parents may have passed on to them a tendency to bring troubles down on themselves.

Medical Research Council Research Fellow,

MICHAEL J OWEN

Department of Biochemistry and Molecular Genetics,

St Mary's Hospital,

London W2 $1 \mathrm{NY}$

Dean,

ROBIN M MURRAY

Institute of Psychiatry,

London SE5 8AF

1 Bertelsen A, Harvald B, Hauge M. A Danish twin study of manic-depressive disorders. $\mathrm{Br}$ Psychiatry 1977;130:330-51

2 Mendelewicz J, Rainer JD. Adoption study supporting genetic transmission in manic-depressive illness. Nature 1977:268:326-9.
3 Gerhard D, Egeland JA, Pauls DL, et al. Is a gene for affective disorder located on the short arm of chromosome 11? Am f Hum Genel 1984;36:350.

+ Gerhard D, Egeland JA. Pauls DL, Housman DE. Search for a gene that predisposes individuals to bipolar disorder. F Psychiatr Res 1987;21:569-75.

5 Egeland JA, Gerhard DS, Pauls DL, et al. Bipolar affective disorders linked to DNA markers on chromosome 11. Nature 1987;325:783-7.

$60^{\prime}$ Malley $\mathrm{K}$, Rotwein $\mathrm{P}$. Human tyrosine hydroxylase and insulin genes are contiguous on chromosome 11. Nucletic Acids Res 1988;16:4437-46.

7 Detera-Wadleigh SD, Berrettini WH, Goldin LR, Boorman D, Anderson S, Gershon ES. Close linkage of C-Harvey-ras-1 and the insulin gene to affective disorder is ruled out in three North American pedigrees. Nature 1987;325:806-8.

8 Hodgkinson S, Sherrington R, Gurling HMD, et al. Molecular genetic evidence for heterogeneity in manic depression. Nature 1987;325:805-6.

9 Baron M, Risch N, Hamburger R, et al. Genetic linkage between X-chromosome markers and bipolar affective illness. Nature 1987;326:289-92.

10 Mendelwicz J, Simon P, Sevy S, et al. Polymorphic DNA markers on X chromosome and manicdepression. Lancet 1987;i:1230-1.

11 Sturt E. McGuffin P. Can linkage and marker association resolve the genetic aetiology of psychiatric disorders? Psychol Med 1985;15:455-62.

12 Blehar MC, Weismann MM, Gershon ES, Hirschfield RMA. Family and genetic studies of affective disorders. Arch Gen Psychiatry 1988:45:289-92.

3 McGuiffin P, Katz R, Bebbington P. The Camberwell Collaborative Depression Study III depression and adversitv in the relatives of depressed probands. Br f Psychiatry 1988;152:775-82.

\section{Anderson-Fabry disease}

\section{A commonly missed diagnosis}

Angiokeratomata, the vascular skin lesions characteristic of Anderson-Fabry disease, an unusual X linked lysosomal storage disorder, were first described in $1898 . .^{12}$ Deficient activity of the lysosomal hydrolase $\alpha$-galactosidase $A$ results in the progressive deposition of uncleaved, neutral glycosphingolipids (predominantly $\alpha$-galactosyl-lactosyl ceramide (trihexosyl ceramide)) within the lysosomes of endothelial, perithelial, and smooth muscle cells, producing the clinical manifestations of the disease. ${ }^{3}$ Skin lesions cluster in the "bathing trunk" area and are often overlooked. Affected males have pain and paraesthesiae in the extremities and may be labelled as neurotic. Diagnosis is often delayed until renal failure or the cerebrovascular complications of the disease develop. The mean age at diagnosis in index cases from 30 large pedigrees known to us was 29 years. One third presented with proteinuria and a diagnosis based on renal histopathological examination.

Most women who are carriers are without symptoms, but they often have clinical evidence of the disease; in a few this may be as severe as in men. ${ }^{+}$The carrier state may be diagnosed by detecting a corneal dystrophy (cornea verticillata) on examination with a slit lamp and by showing reduced leucocyte $\alpha$-galactosidase A activity, although there is considerable overlap with the lower end of the normal range. Genetic counselling remains the cornerstone of management supported by biochemical prenatal diagnosis on amniocytes or chorionic villi. ${ }^{5}$

The gene responsible for expressing $\alpha$-galactosidase $\mathrm{A}$ has been localised to the middle of the long arm of the $\mathrm{X}$ chromosome $^{6-8}$ Studies of linkage have identified cDNA markers that could provide a simple method of diagnosing the disease in carriers or affected fetuses in informative pedigrees..$^{9 \cdot 11}$

There is no specific treatment for Anderson-Fabry disease, and the average life expectancy of affected men was 42 years before renal replacement treatment became available. ${ }^{12}$ Treatment is symptomatic, and painful crises often respond to conventional doses of phenytoin or carbamazepine, or both. ${ }^{1314}$

Deposition of sphingolipid in vascular endothelium activates platelets, contributing to embolic or thrombotic cerebrovascular events. ${ }^{1516}$ The early use of antiplatelet agents, such as aspirin, seems a rational prophylactic approach. Cardiac abnormalities, including disturbances in conduction and valvular disease, are common, ${ }^{1718}$ and we recommend that affected patients and carriers should be assessed by echocardiography if a murmur is detected clinically. Standard advice on dental and surgical antibiotic prophylaxis should be given.

Renal transplantation is appropriate when end stage renal failure develops, although Maizel et al have reported a high incidence of sepsis and failure after transplantation. ${ }^{19}$ Anecdotal reports of improvement in symptoms and transient increases in plasma $\alpha$-galactosidase A activity after transplantation are numerous but not substantiated in most patients; and reaccumulation of ceramide has been observed in the transplanted kidney. ${ }^{2021}$ Enzyme replacement treatment has been explored with human plasma or $\alpha$-galactosidase A extracted from spleen or placenta, but the results have been unsatisfactory. ${ }^{22}{ }^{23}$ Fetal liver transplantation has been similarly unrewarding in three adult patients followed long term..$^{2+25}$

A complementary DNA that encodes mature $\alpha$-galactosidase $\mathrm{A}$ has been cloned and sequenced. ${ }^{26}$ This should facilitate analysis of the structure, organisation, and expression of the normal and mutant gene ${ }^{27}$ and help delineate the nature of lysosomal enzyme biosynthesis and molecular recognition of events that are part of lysosomal intracellular processing. This basic scientific work should allow the eventual development of gene therapy with somatic cells. ${ }^{28} 29$ Meanwhile, early recognition of this metabolic disorder would prevent much personal distress and loss of time from school and work. It would also facilitate early referral for genetic counselling and avoid regretted decisions in family planning.

Medical Research Council Clinical Scientist and

STEPHEN H MORGAN

Honorary Senior Registrar in Medicine,

Division of Inherited Metabolic Diseases,

Clinical Research Centre,

Middlesex HAl 3UJ

Consultant Clinical Geneticist,

MARTIN d'A CRAWFURD

Kennedy Galton Centre,

Northwick Park Hospital, and

Division of Inherited Metabolic Diseases,

Clinical Research Centre

Middlesex HAl 3 UJ 